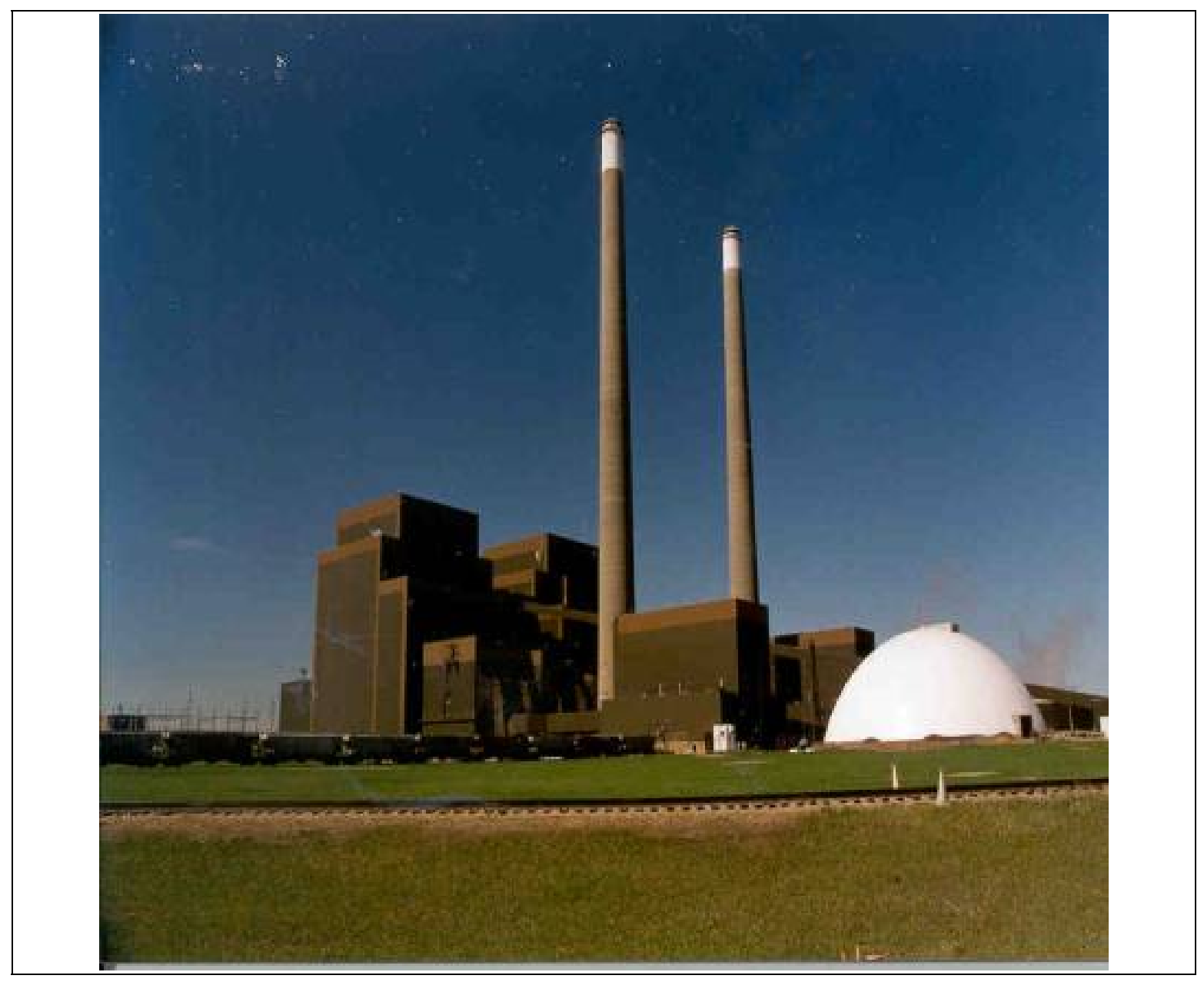

\title{
Lignite Fuel Enhancement
}

\section{Quarterly Technical Progress Report:}

Period: October 1st, 2005 to December 31st, 2005

DOE Award Number: DE-FC26-04NT41763

Date: February 3rd, 2006

\section{Reported by:}

Charles Bullinger, P.E.

Engineering Services Leader/Lignite Fuel Enhancement Project Manager Great River Energy - Coal Creek Station

2875 Third Street SW

Underwood, North Dakota 58576-9659

Telephone: 701-442-7001 


\section{Lignite Fuel Enhancement}

\section{Disclaimer}

"This report was prepared as an account of work sponsored by an agency of the United States Government. Neither the United States Government nor any agency thereof, nor any of their employees, makes any warranty, express or implied, or assumes any legal liability or responsibility for the accuracy, completeness, or usefulness of any information, apparatus, product, or process disclosed, or represents that its use would not infringe privately owned rights. Reference herein to any specific commercial product, process, or service by trade name, trademark, manufacturer, or otherwise does not necessarily constitute or imply its endorsement, recommendation, or favoring by the United States Government or any agency thereof. The views and opinions of authors expressed herein do not necessarily state or reflect those of the United States Government or any agency thereof." 


\section{Abstract}

This 6th quarterly Technical Progress Report for the Lignite Fuel Enhancement Project summarizes activities from October $1^{\text {st }}$ through December 31 st of 2005 . It also summarizes the subsequent purchasing activity and dryer/process construction. 


\section{Acknowledgement}

The authors wish to acknowledge the contributions and support provided by various project managers: Dr. Sai Gollakota (DOE), Matt Coughlin (Barr) Dave Rian (Barr), John Wheeldon (EPRI), Tony Armor (EPRI) and Mark Ness (GRE). 


\section{$\underline{\text { Table of Contents }}$}

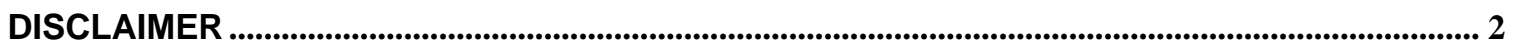

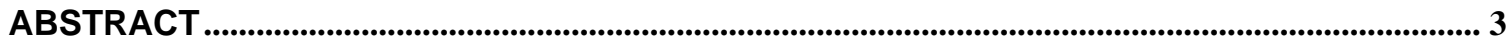

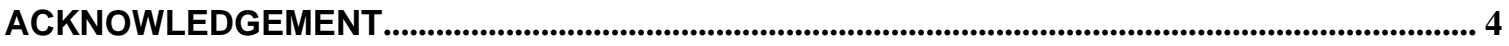

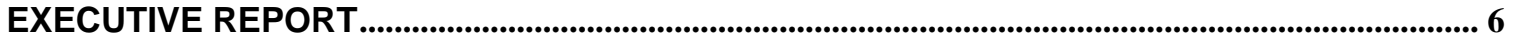

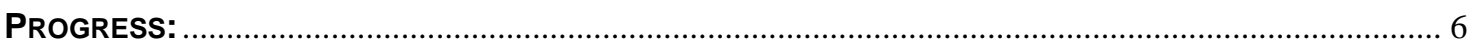

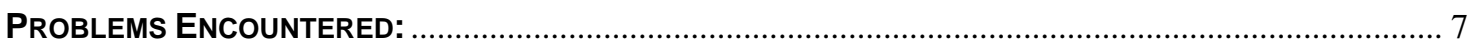

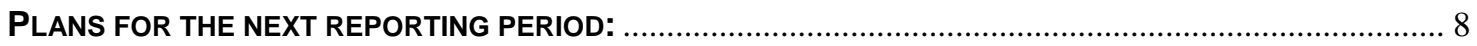

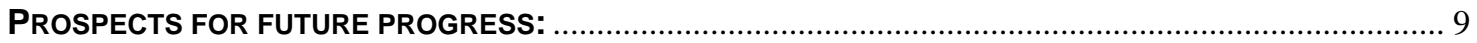

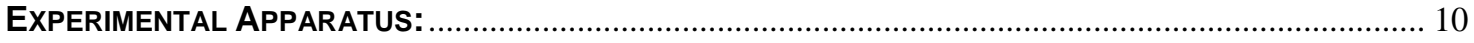

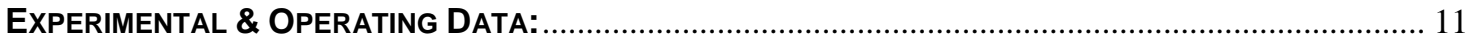

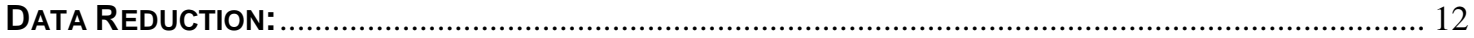

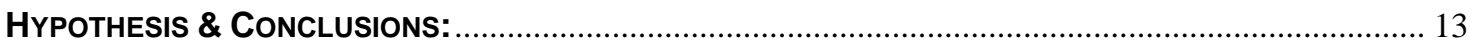




\section{Executive Report}

\section{Progress:}

The Design Team did not conference this quarter due to construction activities dominating the quarter. Primary focus this quarter was the construction/installation. Phase 1 extension recommendation, and subsequent new project estimate, Forms 424 and 4600 were submitted to Ms. Zysk. The NETL technology team subsequently agreed that the increase is justified and made their recommendation to DOE HQ.

All major mechanical equipment was installed this quarter. All five in-bed coils were installed. Conveyors to and from the dryer were installed. All wiring was completed. Instrumentation checkout and equipment run has begun. The dividing wall between the Air Heater and Dryer equipment was completed. Preliminary checkout of the control system was begun with Honeywell's help. Water and air systems were charged.

Great River Energy and Headwaters met to discuss the Commercialization Plan in December. Tier 1, 2, \& 3 tier utilities were identified as target markets. The MOU agreement was discussed but not finalized. Basin Electric asked for a more detailed discussion of the technology and the Project Manager went to their headquarters in October and presented the technology to them. They believe the technology can fit their future environmental strategy at their lignite burning facilities. A Confidentiality Agreement has been drafted.

Major pieces of equipment received this quarter included the explosion suppression system, dividing wall, and the last of the in-bed-coils..

Invoices \#12 through \#17 are completed but being held pending DOE approval of additional project costs...Phase 1 extension and overrun request was submitted to the NETL last quarter. DOE headquarters is reviewing the recommendation to support additional project overrun.

Charles Bullinger gave a presentation of the GRE technology to Basin Electric as previously mentioned. An overview of project plans was explained with emphasis made on our belief that this same technology should help their presumptive BART environmental submittal. EPRI has been making plans to "sunrise" a Dryer Interest Group in 2006. 


\section{Problems Encountered:}

Lehigh assignment agreement has been signed and negotiation of the Master Agreement is near completion. Drawing delays, maintenance requests, procurement delays and problems with in-situ installation delayed construction from predicted but by the end of December all major equipment was installed. The fire protection sprinkler schedule was delayed. 
Plans for the next reporting period:

The Dryer system installation will complete in early January: mechanical did in December and electrical to follow. $\mathrm{ICl}$ electricians will complete instrument checkout and equipment signal verification. All equipment will be test driven and run from the Control Room. Honeywell system checkout should complete in January. "Shakedown" testing of the system will complete and the $1^{\text {st }}$ lignite will be run through the system to Pulverizer 26 in late January. Phase 1 extension approval should be completed next quarter. 


\section{Prospects for future progress:}

The prospects are quite good that all the next Quarter deliverables will be met. Equipment installation and checkout should complete and the testing protocol begun. 


\section{Experimental Apparatus:}

Details of the dryer and system, P\&ID's, schematics, and drawings contain "Limited Rights" information which cannot be disclosed at this particular time.

Installation of the Control Room

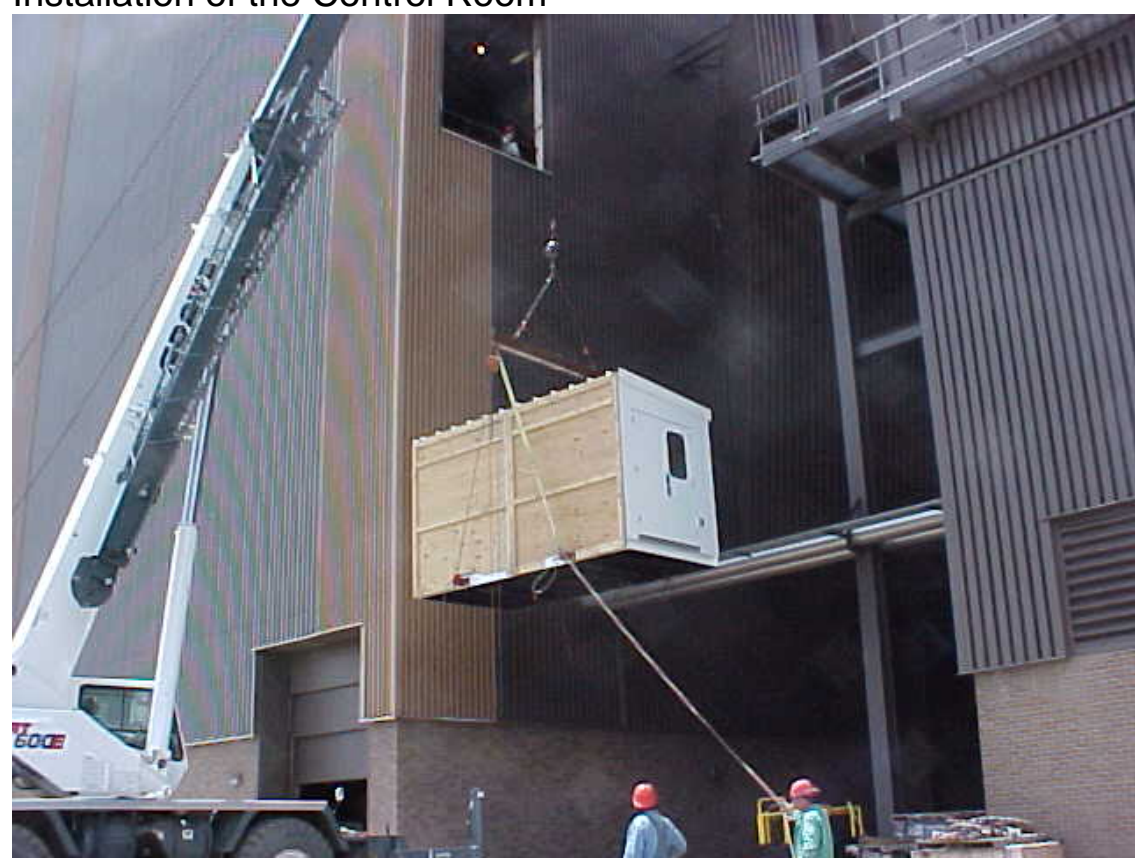

Installation of the Exhaust Fan

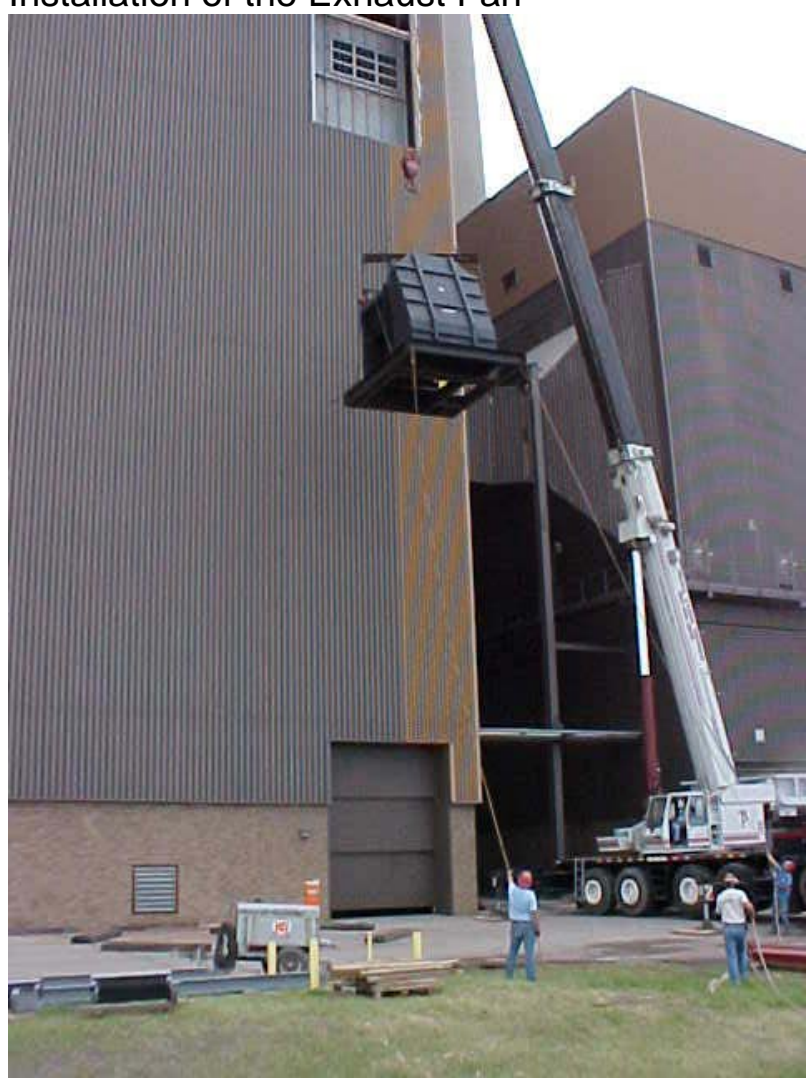




\section{Experimental \& Operating Data:}

Construction phase currently ongoing therefore no data to report at this time. 
Data Reduction:

No data 


\section{Hypothesis \& Conclusions:}

Hypothesis remains the same. We will be able to dry lignite an increment to benefit the performance of and reduce emissions from a coal burning electric power generating station. 